\title{
FULLY AUTOMATED SYSTEM FOR SHIELD TUNNELLING UNDER INTEGRATED CONTROL
}

\author{
Hiroshi OHNO, Keizo KAZAMA, Akihiro HIGASHIDE and Akira TOMIOKA \\ Civil Engineering Technical Dept., OBAYASHI CORP. \\ Kozaburo TSUCHIYA \\ Civil Engineering Construction Div., OBAYASHI CORP.
}

\begin{abstract}
In recent years, with the overcrowding of cities in Japan, the use of underground space has become more and more intensive. As a result, the shield tunnelling method has been increasingly used for underground development. Also recently, the diameter of shield tunnels has increased, and the conditions under which the tunnels are constructed have become increasingly difficult. This has led to an increased need for automation technology to achieve labor savings and labor reductions, as well as achieving improvements in safety and precision. To meet these various needs, the authors have, since 1980 , been involved in extensive research and development of shield tunnel automation, and has so far developed and put to practical use such developments as the Shield Machine Automatic Direction Control System, Automatic Segment Conveying System and Automatic Segment Erection Robot. This paper introduces a comprehensive automatic shield tunneling system that enables almost completely automatic shield tunnel construction by the integration of the above mentioned systems.
\end{abstract}

\section{INTRODUCTION}

With the increasing congestion of Japanese cities in recent years, the shield tunneling method has become indispensable in the development of underground space for providing the basic social infrastructure. Shield tunnel projects have been increasing in scale, and with the need to carry out excavation in the close proximity of existing underground structures, the development of shield tunneling in Japan did not only focus on labor saving and reduction, but also had to improve safety and quality of construction. In order to meet these needs, the authors developed a fully automated system for the entire shield construction process. 


\section{BACKGROUND TO THE DEVELOPMENT}

Shield tunneling involves the repetition of a single process, the work environment is relatively fixed, the materials and equipment used are few, and the main structural member (the tunnel segment) is prefabricated. These features result in a construction process that has been highly mechanized from the beginning. For this reason, the development of automation technology in shield tunneling in Japan has been underway for quite some time, and a considerable number of developments have been put to actual use.

However, the technology developed so far has concentrated on automation of the individual operations of the shield tunneling process, not on the continuous automation of the entire process. For this reason, the benefits have often not matched the considerable investment made in the introduction of the automation technology.

Therefore the aim of the authors was to develop a comprehensive automatic shield tunneling system by the integration of such developments as the Shield Machine Automatic Direction Control System, Automatic Segment Conveying System and Automatic Segment Erection Robot to achieve economical benefits as well as labor saving and reduction, and to improve the safety and quality of construction.

\section{OVERALL SYSTEM STRUCTUR}

The Fully Automated System for shield Tunneling under Integrated Control (FASTIC), as shown in Fig.1, comprises a Shield Machine Automatic Direction Control System, Automatic Segment Conveying System, Automatic Segment Erection Robot and a Multi-Function Ancillary Robot situated behind the cutting face to perform various shield construction works. These various systems and construction robots operate in combination to enable almost total continuous automatic shield tunnel operation. Each system will be described below.

\section{AUTOMATION TECHNOLOGY INCORPORATED IN THE FASTIC}

\subsection{SHIELD MACHINE AUTOMATIC DIRECTION CONTROL SYSTEM}

Generally, in steering the shield machine, the operator must not only adjusts any deviation of the shield machine from its course and its position relative to the completed segments, but he must also consider many other factors when deciding on the most suitable shield jack operating pattern, such as ensuring that the segments providing the reaction force for the shield thrust are not damaged.

The introduction of the shield machine automatic direction control system relies on a computer to perform the complex task of steering the shield, and achieves labor 


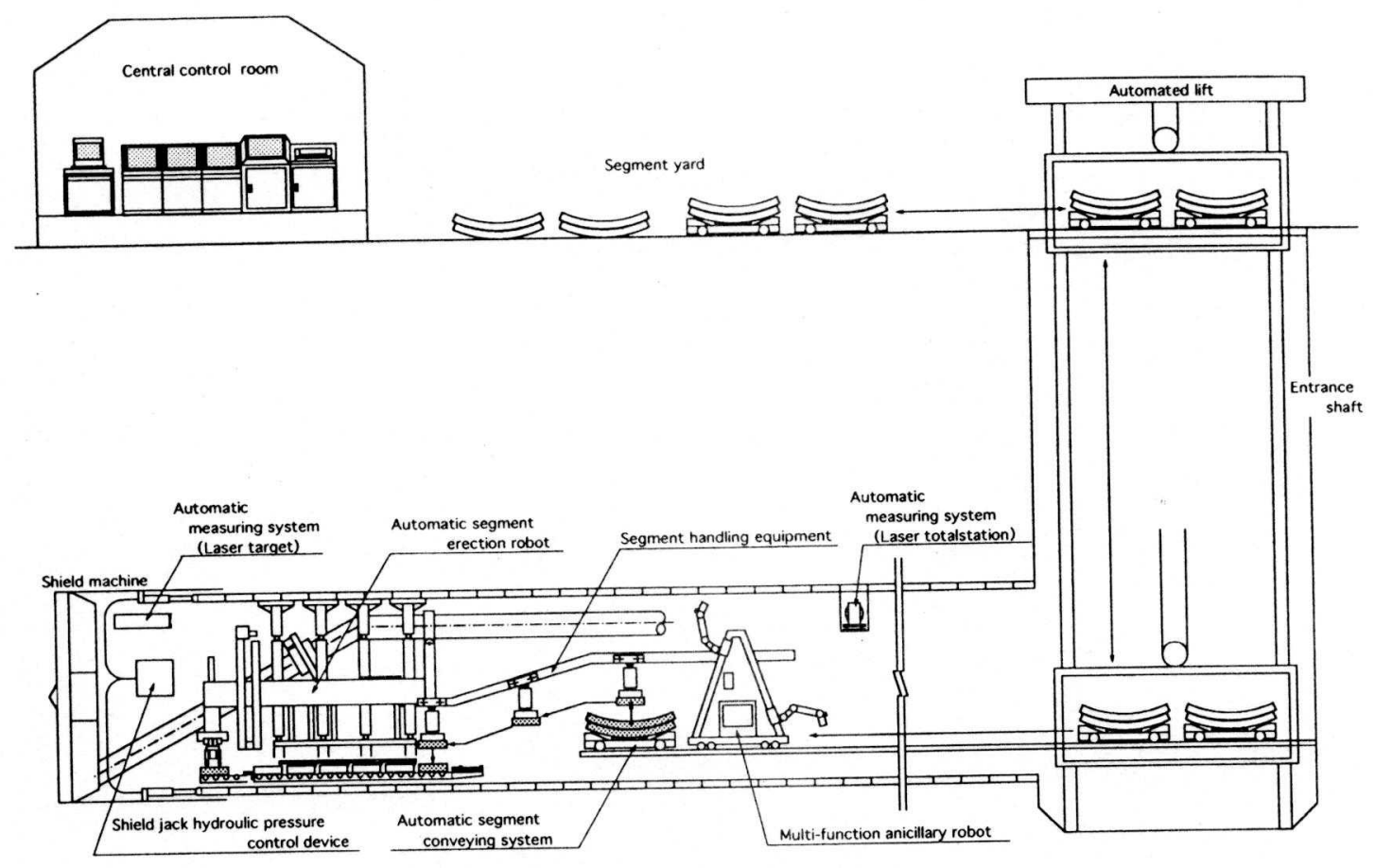

Fig.1 Overall System Schematic

savings as well as improved quality of the construction work.

This Shield Machine Automatic Direction Control System comprises:

*a Automatic Measuring System that provides automatic real-time measurements of the shield machines position and attitude in relation to the design course,

*a Direction Control Computation System that incorporates self-learning of the shield thrust control characteristics and computes the optimum thrust control based on data from the automatic measuring system,

*a Shield Jack Hydraulic Pressure Control Device that controls the shield jack operation.

\subsubsection{AUTOMATIC MEASURING SYSTEM}

The Automatic Measuring System performs computations based on data from automatic measuring instrumentation and displays the deviation from the planned course (amount and angle of deviation) and also provides an external output of this information. The main automatic measuring instrumentation involved is an automatic tracking total station using a laser, a gyro-compass and a level gauge. In particular, the use of an electronic total station and gyro-compass combination for horizontal direction sensing has resulted in a precise, highly reliable and practical system. A schematic of measurement using this system is shown in Fig. 2. 


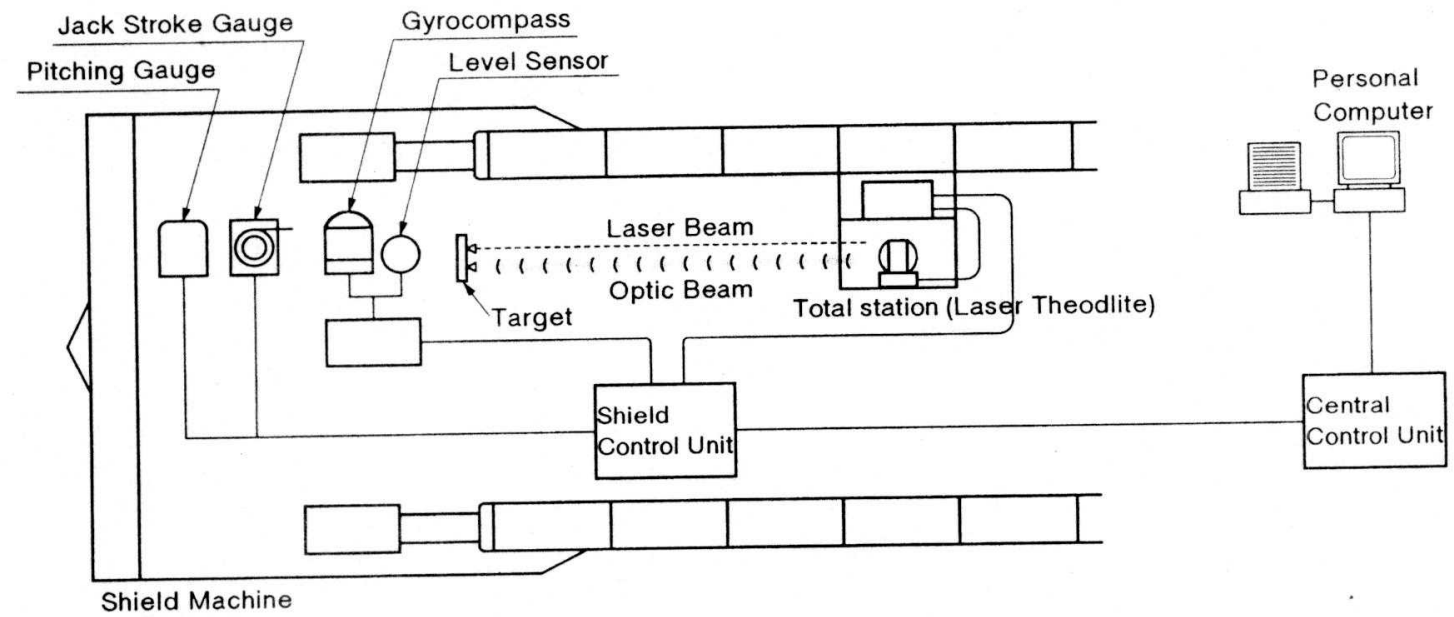

Fig.2 Automatic Measuring System

\subsubsection{DIRECTION CONTROL (INCREMENT) COMPUTATION SYSTEM}

This system determines the control increment necessary to control the jacks to keep the shield machine from straying from the design course, based on the amount and angle of deviation from the design course obtained from the automatic measuring system. Basically, the system comprises an initial control increment computation function and a control increment correction function; combination with fuzzy control enables to control machine position within $2-3 \mathrm{~cm}$ from the design course.

i) Initial Control Increment Computation Function

Based on the amount and angle of deviation from the design course obtained from the automatic measuring system, a target control angle is calculated as shown in Fig.3, as an indicator for determining the shield machine directional control increment. Then, this target control angle, along with various shield machine excavation variables (course shape, shield machine bended angle, amount of copy-cutting etc.) are used as the input values for fuzzy logic inference, and the force point (the central point of the shield jack thrust) is output.

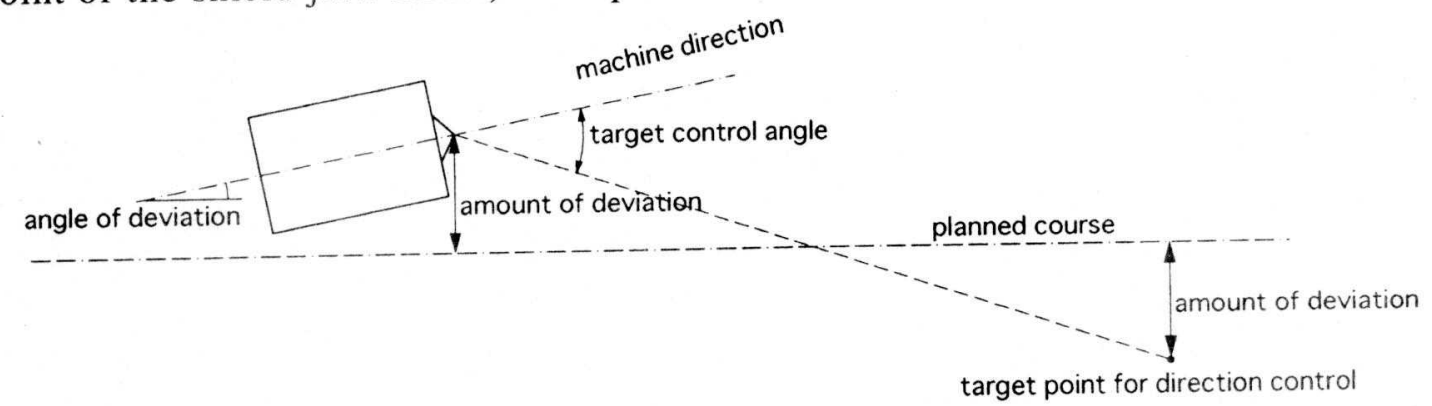

Fig.3 Target Control Angle 
The fuzzy rules have the function of self-learning from previous excavation, enabling control that takes into account prevailing ground conditions and the particular characteristics of the shield machine itself.

ii) Control Increment Correction Function

The behaviour of the shield machine is continually monitored by the automatic measuring system and the initial control increment corrected as necessary. The difference between the target angle on commencement of shield driving (q0) and the target angle after commencement (during shield driving), i.e., the target angle variation (qi$\mathrm{q} 0$ ) is used as the input value for the fuzzy rules to determine the control discrepancy, from which the necessary correction is made to the force point.

\subsubsection{SHIELD JACK HYDRAULIC PRESSURE CONTROL DEVICE}

Generally, shield machines are steered by setting the jack pattern (shield jack ON/OFF pattern) to produce the required force point for the thrust. However, the judgement the pattern for the force point is decided by the operator. The complexity of his task and the level of his experience can cause variations in the control.

It was decided to remove the concept of jack pattern, and instead to adopt a jack hydraulic pressure balance method. As shown in Fig.4, the multiple jacks of the shield machine are formed into jack blocks, and precise control of the hydraulic pressure of each individual block enables the force point to be accurately achieved in accordance with an external command.
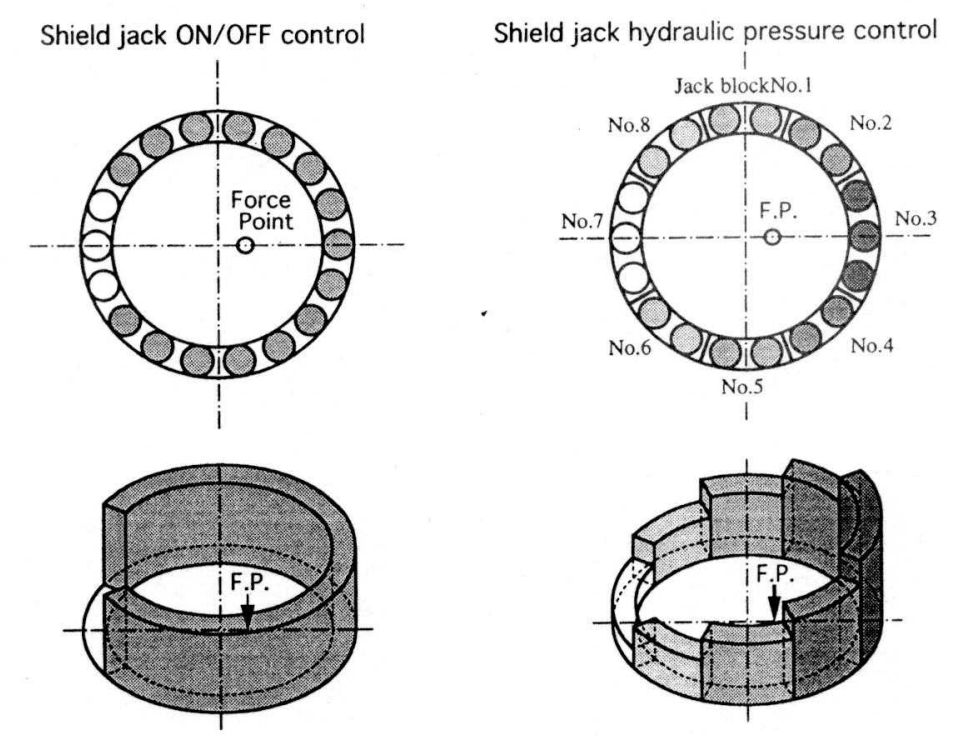

Fig.4 Comparison of ON/OFF Control and Hydraulic Pressure Control 
In addition, a high degree of compatibility has been achieved between this device and the automatic direction control system; the jack thrust being distributed smoothly around the periphery of the shield so that segment loading can be achieved without segment deformation, segment cracking, or opening of joints, consequently resulting in an improvement in tunnel quality.

\subsection{AUTOMATIC SEGMENT CONVEYING/SEGMENT FEEDING SYSTEM}

This system provides full automation of the segment conveying operation (from the entrance of the vertical shaft to the point where the segments are delivered to the segment erection device at the cutting face) without manual labor. In Fig. 5 is shown a flow chart of the system that comprises an AGV (Automated Guided Vehicle) System, Handling Device, and Stock Device. The operating cycle of the system is described below.

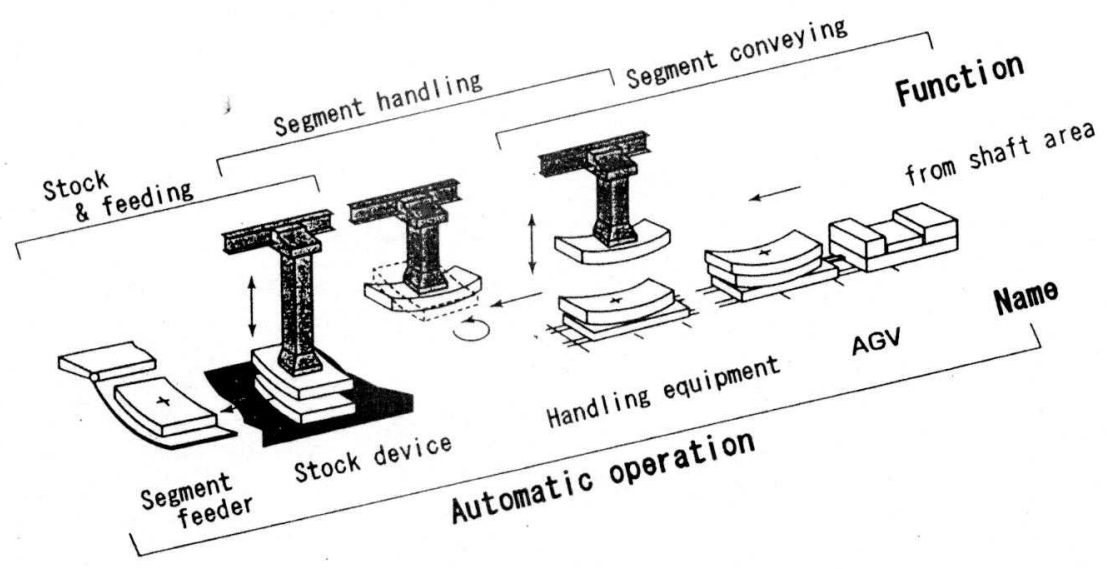

Fig.5 Automatic Segment Conveying and Feeding System - Flow Diagram

\subsubsection{AGV SYSTEM}

The segment is automatically conveyed by the AGV system from the vertical shaft to the position of erector device in a segment wagon where it is unloaded by the segment handling equipment and delivered to the stock device. The system comprises an unmanned battery locomotive and two segment wagons. The feature of this system, as shown in Fig.6, is that the segment wagon incorporates a mechanism for automatic removal of the segment support. The segments are loaded on the wagon in pairs, one above the other. The upper segment is supported by rotating arms instead of the wooden beams that had to be removed by labour. This support is automatically removed when the upper segment has been delivered to the handling device. 


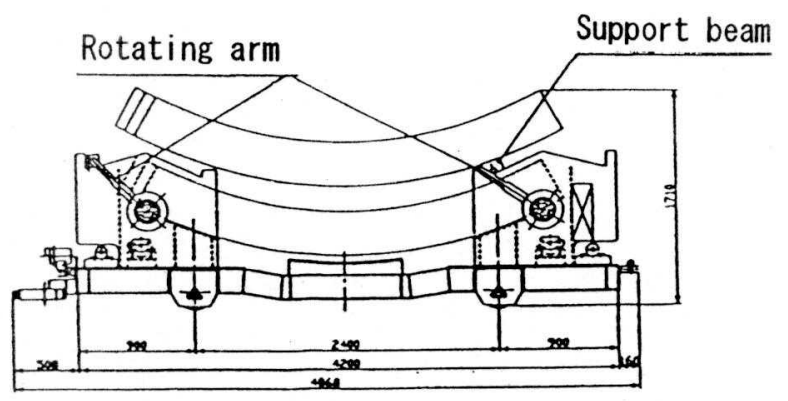

Fig.6 Segment Wagon

\subsubsection{SEGMENT HANDLING EQUIPMENT}

The segment handling equipment uses a suction pad to hold the segments conveyed by the AGV system and deliver them to the stock device. The handling equipment, shown in Fig.7, comprises a locating device(see below), (that senses the segment position), a winch, rotating mechanism, traveling beam, suction mechanism(see below) and a control monitoring panel. The main features of the device are:

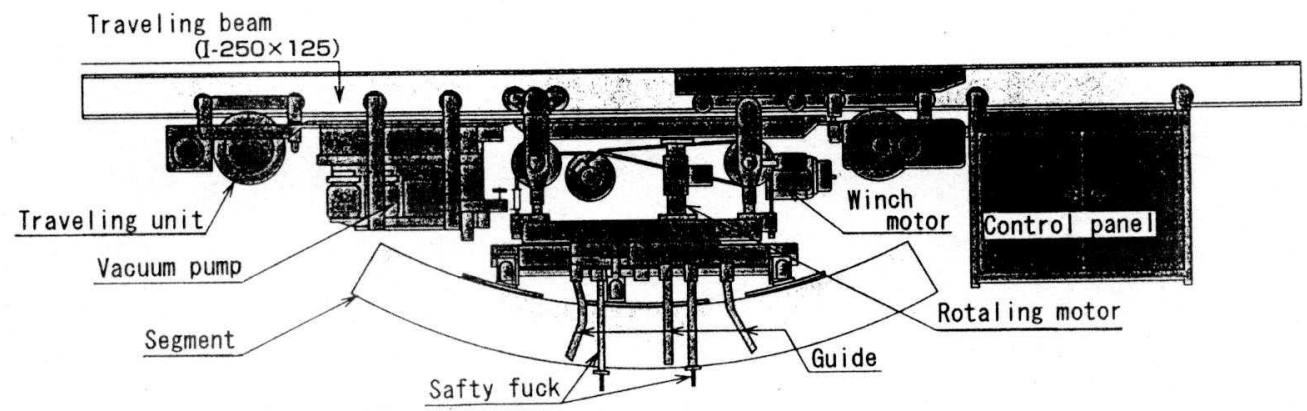

Fig.7 Segment Handling Equipment

\section{i) Locating Device}

The relative position of the segment, eonveyed by the AGV system, and the segment handling equipment is constantly changing due to the progress of the shield machine. This system uses a CCD camera and image processing computer to rapidly determine the position of the segment.

ii) Suction Mechanism

The main feature of the segment handling system is the suction mechanism that uses a suction pad to hold the segment. The use of a suction pad allows a degree of tolerance in the segment location (position sensing) during segment handling and achieves savings in the time spent in segment handling. The specifications of the suction device are given in Table 1 . 
Table 1 Specification of Suction Device

\begin{tabular}{|c|c|c|}
\hline suction pump unit & $\begin{array}{l}\text { suction power } \\
\text { suction pressur } \\
\text { electrical power unit } \\
\text { suction chamber volume }\end{array}$ & $\begin{array}{l}480 \mathrm{l} / \mathrm{min} \\
550 \sim 600 \mathrm{mmHg} \\
0.3 \mathrm{kw} \times 2 \\
150 \mathrm{~L} \\
\end{array}$ \\
\hline \multirow[t]{3}{*}{ suction pad } & $\begin{array}{l}\text { center pad } \\
\text { pad size } \\
\text { lift up force }\end{array}$ & $\begin{array}{l}\text { 1. } 487 \mathrm{~cm}^{2} \\
\text { 1. } 112 \mathrm{kgf}(550 \mathrm{mmHg})\end{array}$ \\
\hline & $\begin{array}{l}\text { right \& left pad } \\
\text { pad size } \\
\text { lift up force }\end{array}$ & $\begin{array}{l}4,000 \mathrm{~cm}^{2} \times 2 \\
2,990 \mathrm{kgf} \times 2 \quad(550 \mathrm{mmHg})\end{array}$ \\
\hline & total lift up force & $7,092 \mathrm{kgf}(550 \mathrm{mmHg})$ \\
\hline travelling unit & travelling speed & $15 \mathrm{~m} / \mathrm{min}$ \\
\hline
\end{tabular}

\subsubsection{STOCK DEVICE}

This device stockpiles the segments as they are off-loaded from the segment wagon, and delivers them one by one to the segment feeder during segment erection.

\subsection{AUTOMATIC SEGMENT ERECTION ROBOT}

The erector device takes the segment from the segment feeder, places the segment in position, and tightens the bolts in one continuous automatic process. To reduce segment erection time and achieve versatility of operation, the structure of the robot is independent of the shield machine. As shown in Fig.8, the robot comprises erector equipment, self supporting equipment, and a segment feeder.

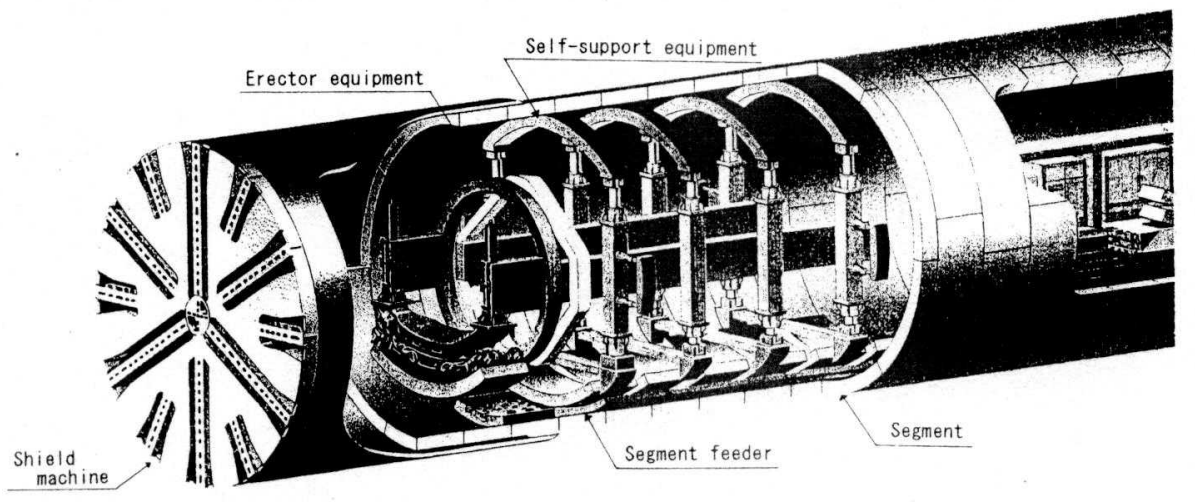

Fig.8 Independent Automatic Segment Erection Robot

The main features of the robot are:

i) As the relative positions of the robot and previously erected segments is maintained constant, attitude correction to position the rotating surface of the erector in relation to the previously erected segment edge needs only to be carried out once, achieving considerable time savings.

ii) Time savings are also made possible during erection, by control of segment posi- 
tioning and bolt insertion.

iii) To improve operating speed and achieve reliability, a high level of control sophistication has been achieved by the use of AI (artificial intelligence).

iv) As the robot is fixed within the previously erected segments, segment erection can be carried out simultaneously with shield excavation.

v) As the structure of the robot is independent of the shield machine, it can be utilized for multiple projects with relative ease.

\subsection{MULTI-FUNCTION ANCILLARY ROBOT}

Situated behind the position of erector equipment, the purpose of this robot, unlike the systems and robot described above that were developed for automation of the main shield tunneling tasks, is to perform shield construction incidental work such as retightening of segment bolts or the laying of sleepers and rails. An outline of this robot and an example of its use as a bolt tightening robot are described below.

\subsubsection{OUTLINE OF THE MULTI-FUNCTION ANCILLARY ROBOT}

This robot is a large handling manipulator with a rated load of $500 \mathrm{~kg}$, able to handle an object of maximum $750 \mathrm{~kg}$ and position it quickly with an accuracy of within $0.1 \mathrm{~mm}$. The structure of the arm is shown in Figure 9 and has the following characteristics:

i) This vertically moved multi-joint robot has 3 joints and 6 degrees of freedom.

ii) Using an image sensor and an ultrasonic sensor incorporated in the end of the manipulator, loads of $500 \mathrm{~kg}$ can be positioned with an accuracy of $0.1 \mathrm{~mm}$.

iii) One robot can be used for various tasks by changing the end attachment.

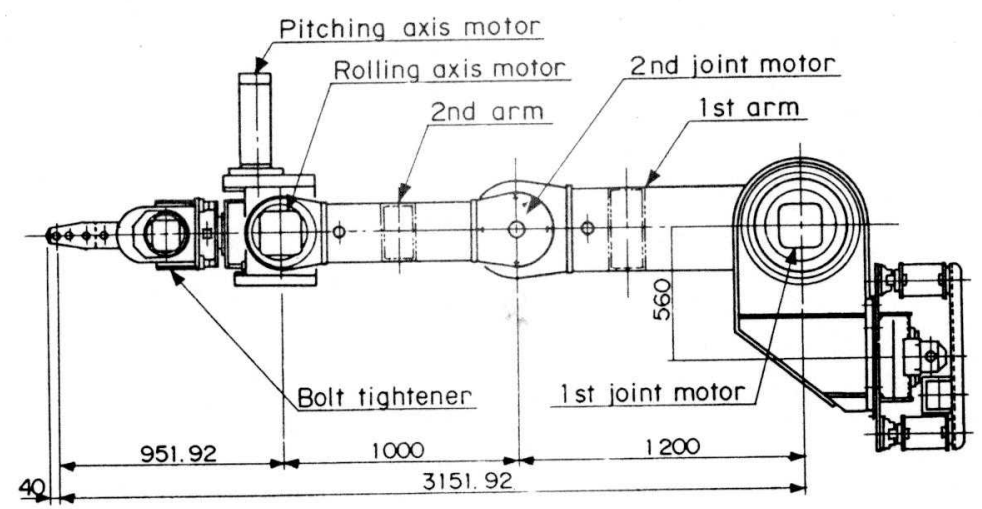

Fig.9 Multi-Function Handling Robot

\subsubsection{OUTLINE OF THE ROBOT FOR SEGMENT BOLT TIGHTENING}

With the increasing size of shield tunnels the number of inter-segment bolts has increased, and they require a torque which is too high for manual work. These facts, 
coupled with the fact that the work is carried out in high places, means the work must be performed in conditions of considerable difficulty for human labor. In order to avoid the need for this difficult and dangerous work, it was decided to use the multifunction ancillary robot for segment bolt tightening. An overall schematic of the robot is shown in Figure 10. Two handling robots are incorporated, one on each side of the free-running support cart, and each robot is fitted with a bolt tightening attachment. The robots confirm the position of the bolts using their sensors and then tighten the bolts; the process being fully automatic. It has been verified that in this way one robot is capable of tightening 60 bolts in one hour.

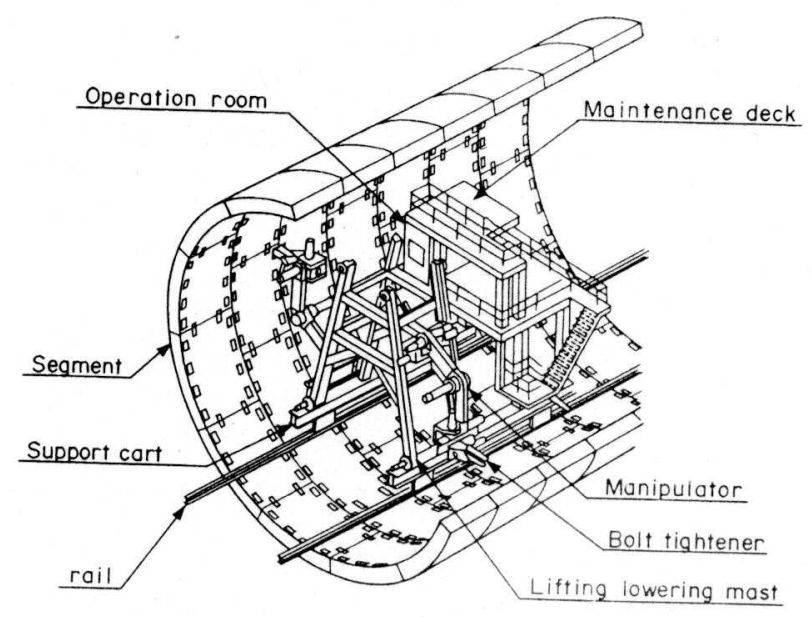

Fig.10 Segment Bolt Tightening Robot

\section{THE EFFECTIVENESS OF THE SYSTEM AND FUTUR DEVELOPMENT PLANS}

The use of the fully automated system for shield tunneling under integrated control enabled verification of the following:

i) The automation and use of robots, not only for the main operations of shield tunneling but also for the intermediate operations such as segment conveying and segment feeding, enabled the unmanned shield process to be carried out with considerable labor savings.

ii) The introduction of systems such as the automatic direction system and the automatic segment erection system resulted in improved in quality and precision that are reflected in the quality of the finished tunnel.

iii) The introduction of the segment conveying and feeder system, automatic erection system, and robot for tightening of the segment bolts obviate the need for manual labor, contributing to the overall safety of the shield tunneling work.

As described above, the integration of shield tunnel automation technology has been successfully completed. However, as the cost effectiveness of this research and the introduction of this technology has not been a major objective, it remains necessary to develop simplified equipment to achieve the same result and to develop a more general-purpose system. 